\title{
RETRACTED ARTICLE: Structural and contact analysis of a three-dimensional disc-pad model with and without thermal effects
}

\author{
Ali BELHOCINE ${ }^{1, *}$, Mesut DUZGUN ${ }^{2}$, Nouby Mahdi GHAZALY ${ }^{3}$, Oday Ibraheem. ABDULLAH ${ }^{4}$ \\ ${ }^{1}$ Faculty of Mechanical Engineering, University of Sciences and the Technology of Oran, L.P 1505 El - MNAOUER, USTO 31000 ORAN, \\ Algeria \\ ${ }^{2}$ Automotive Engineering Department, Faculty of Technology, Gazi University 06500, Ankara, Turkey \\ ${ }^{3}$ Mechanical Engineering Dept., Faculty of Engineering, South Valley University, Qena-83523, Egypt \\ ${ }^{4}$ System Technology and Mechanical Design Methodology, Hamburg University of Technology, Germany \\ Received: 19 August 2014 / Revised: 03 November 2014 / Accepted: 30 December 2014 \\ (C) The author(s) 2015. This article is published with open access at Springerlink.com
}

This article has been retracted at the request of the Editor-in-chief, since substantial parts of this article were previously published in Tribology in Industry: A. Belhocine, N.M. Ghazali, O.I. Abdullah. Structural and Contact Analysis of a 3-Dimensional Disc-Pad Model with and without Thermal Effects. 2014. Tribology in Industry 36(4): 406-418 (2014). 